\title{
$\mathbb{A}$ Economics Bulletin
}

\author{
Volume 36, Issue 1
}

\section{Long-term Growth Effects of Natural Disasters - Empirical Evidence for Droughts}

\author{
Michael Berlemann \\ Helmut-Schmidt-University Hamburg
}

\author{
Daniela Wenzel \\ Helmut-Schmidt-University Hamburg
}

\begin{abstract}
The ongoing process of climate change goes along with a higher frequency and/or severity of droughts. While the short-term growth consequences of droughts are comparatively well examined, little research has yet been devoted to the question whether and how droughts affect medium and long-term growth. However, knowledge on the growth dynamics triggered by natural disasters is an influential input factor for integrated assessment models which are used to evaluate climate policy measures. In this paper we deliver empirical support for the hypothesis of the existence of long-run growth effects of droughts. Based on a panel of 153 countries over the period of 1960 to 2002 and employing a truly exogenous drought indicator derived from rainfall data we find significantly negative long-term growth effects of droughts in both highly and less developed countries. We also deliver first empirical evidence on the channels through which droughts affect economic growth.
\end{abstract}

Financial support by the German Federal Ministry of Education and Research is gratefully acknowledged.

Citation: Michael Berlemann and Daniela Wenzel, (2016) "Long-term Growth Effects of Natural Disasters - Empirical Evidence for Droughts ", Economics Bulletin, Volume 36, Issue 1, pages 464-476

Contact: Michael Berlemann - Michael.Berlemann@hsu-hh.de, Daniela Wenzel- danwen@hsu-hh.de.

Submitted: June 10, 2015. Published: March 17, 2016. 


\section{Introduction}

A likely consequence of the ongoing process of climate change is an increased frequency and/or severity of certain types of natural disasters and extreme weather events (Thomas 2014). Against this backdrop, there has been an increasing interest in the question of whether and how natural disasters affect economic growth. Most of the existing empirical evidence concerns the shortterm effects of natural disasters and tends to find negative short-term growth effects of natural disasters (see, e.g., Felbermayr and Gröschl 2014). Much less empirical evidence is available on the long-term growth effects of natural disasters. Moreover, the few existing empirical studies deliver mixed results. In their cross-sectional study of 89 countries, the pioneering paper by Skidmore and Toya (2002) finds different results for climatic and geologic disasters. Whereas the frequency of climatic natural disasters turns out to have a positive effect on economic growth, geologic disasters tend to have a negative although insignificant impact on economic growth. Noy and Nualsri (2007) find negative growth impacts of natural disasters with high casualty numbers but no significant effects of disasters damaging the capital stock. Similar results are reported in Jaramillo (2009). However, Raddatz (2009) finds climatic disasters to have a negative long-run impact on economic growth. In their review of the related literature, Cavallo and Noy (2010) conclude "A further significant lacuna in the current state of our knowledge is the absence of any agreement regarding the long-run effects of these disasters".

One might suspect that three reasons are responsible for the relatively mixed picture. First, it seems to be questionable to treat all (climatic) disasters as homogenous, as one might easily imagine different disasters to affect economic development differently. Second and even more problematic, inappropriate measurement of natural disaster severity might have contributed to the yet ambiguous results (see also Cavallo and Noy 2010). The vast majority of existing studies relies on data from the EM-DAT database. As Strobl (2012) argues, the EM-DAT data was collected from various different sources and thus is likely contaminated with measurement error since the reporting sources differ in their motives, methodologies and quality of reporting disaster damages. Moreover, using the EM-DAT disasters intensity indicators likely leads to an endogeneity problem in growth regressions as (i) the monetized damage of a disaster and (ii) insurance coverage and thus the probability of inclusion into the database depend on per capita GDP, the dependent variable in growth regressions (Felbermayr and Gröschl 2014). Third, by far the most empirical studies of the growth effects of natural disasters regress GDP growth on a number of control variables (such as the saving rate, fertility or human capital) and add a measure of disaster frequency or severity to the estimation equation. As the effect of natural disasters on economic growth might work through exactly these control variables, an "overcontrolling problem" is likely to occur which might result in insignificant effects of the disaster indicator (Dell, Jones and Olken 2014).

In a recent paper Hsiang and Jina (2014) show how these problems can be tackled adequately. In their study the authors concentrate on one type of natural disasters, tropical cyclones. Instead of using EM-DAT data the authors rely on truly exogenous meteorological measures of cyclone severity. And finally, the authors refrain from using control variables in their 
main analysis and get rid of cross-country and time variance by applying time and country-fixed effects, a solution which has also been proposed by Dell, Jones and Olken (2014).

In this paper we study the effect of droughts on long-term economic growth. We thereby follow the approach of Hsiang and Jina (2014) and identify droughts on the basis of a rainfallindicator. In our baseline panel regression approach we refrain from using possibly multicollinear control variables. We find robust empirical evidence in favor of the hypothesis that droughts depress long-term economic growth in both highly developed and less developed countries. We also shed light on the channels through which droughts affect economic growth.

The remainder of the paper is organized as follows. In the second section, we outline the estimation approach and present the employed data. Section three delivers the estimation results. Section four analyzes growth effects in different country groups and section five is concerned with possible transmission channels. Section six summarizes.

\section{Estimation Approach and Data}

Our estimation approach consists of estimating panel regressions of the type:

$$
\ln G D P_{t, i}-\ln G D P_{t-1, i}=\alpha_{i}+\beta_{t}+\gamma \cdot D_{i, t, k}+\varepsilon_{i, t}
$$

where In GDP is the natural logarithm of the per capita gross domestic product in country $i$ at time $t, \alpha_{i}$ is a country fixed effect controlling for countries' differing institutions, cultures and geographies, $\beta_{t}$ are time fixed effects, $D_{i, t, k}$ is an indicator of drought severity in the actual and the $\mathrm{k}$ preceding years and $\varepsilon_{\mathrm{i}, \mathrm{t}}$ is the unexplained residual. In order to control for autocorrelation for up to 10 years and heteroscedasticity we estimate the model using ordinary least squares and HAC standard errors (Newey and West 1987). We also control for possible spatial correlation within a distance of 1,000 km (Conley 1999, Hsiang 2010 and Fetzer 2014).

The variable of central interest, the meteorological drought indicator $D_{i, t, k}$ is constructed from data provided by the International Research Institute for Climate and Society (IRI). Different from the often employed disaster indicators from the EM-DAT database our indicator is by construction exogenous as it is calculated solely on the basis of precipitation data, which itself is unaffected by economic growth. We make use of the Standardized Precipitation Index (SPI) which was initially developed by McKee, Doesken and Kleist (1993) and was recommended by the leading researchers in the field in the Lincoln Declaration on Drought Indices (World Meteorological Organization 2012). Our drought indicator at time $t$ is defined as the average of the absolute value of the sum of all negative 12-month-SPI-values over the actual and the $\mathrm{k}$ preceding years in country i (per mio. sqkm):

$$
D_{i, t, k}=\frac{\sum_{j=0}^{k} \sum_{m=1}^{12}\left|S P I_{i, t-k, m}^{\text {neg. }}\right|}{k+1}
$$

The utilization of this sort of indicator allows us identifying whether droughts affect economic growth only in the very short-run (in this case only the versions of the indicator including the 
directly preceding years should turn out to be significant) or whether the medium and long-run disaster history is (also) relevant.

We use Penn World Tables Version 8.0 as source of GDP data (Feenstra, Inklaar and Timmer 2015) and construct our left hand variable from GDP per capita in constant prices of 2005 (RGDPNA). For the initial level of GDP per capita we use current GDP (output side, current PPP). For stability tests we also use the standard set of control variables, e.g. the investment share of real GDP per capita (PWT 8.0), the government share of real GDP per capita (PWT 8.0), the net fertility rate (World Development Indicators, calculated) and the average years of total schooling (Barro and Lee 2013, linearly interpolated). Table 1 delivers summary statistics of the employed dataset.

Table 1: Summary statistics of employed dataset

\begin{tabular}{|l|c|c|c|c|c|}
\hline Variable & Obs. & Mean & Std. Dev. & Min & Max \\
\hline Real GDP per capita (RGDPNA), prices of 2005 & 4665 & 0,04 & 0,07 & $-1,08$ & 0,72 \\
\hline Log of current GDP, output side (current PPP) & 4788 & 9,59 & 1,91 & 3,96 & 15,44 \\
\hline Sum of neg. SPI-values (abs. value per mio. sqkm) & 6063 & 2857,42 & 3221,95 & 0,00 & 72237,38 \\
\hline Investment share in real GDP per capita (RGDPL), \% & 4787 & 0,18 & 0,11 & 0,01 & 1,40 \\
\hline Gov. share in real GDP per capita (RGDPL), \% & 4788 & 0,21 & 0,13 & 0,01 & 1,44 \\
\hline Net fertility rate & 4453 & 4,16 & 1,48 & 1,06 & 7,79 \\
\hline Avg. years of total schooling, linearly interpolated & 5194 & 4,43 & 2,82 & 0,02 & 12,71 \\
\hline
\end{tabular}

Sources: International Research Institute for Climate and Society, Penn World Tables 8.0, World Development Indicators, Barro and Lee 2013.

Altogether, our unbalanced panel dataset consists of data from 153 countries and covers the years of 1960 to $2002 .^{1}$ The number of years included differs in between 12 and 43.

\section{Estimation Results}

Figure 1 summarizes the results of our baseline panel estimation and two additional specifications of model (1). ${ }^{2}$ In the upper part we show the coefficients of the baseline model with two-way fixed effects and without any control variables. ${ }^{3}$ All coefficients turn out to be negative, and, with the exception of the one-period lagged version, are significant on at least the $90 \%$-confidencelevel. Moreover, the effects are comparatively large as an increase of one standard deviation in the drought indicator leads to negative growth effects in between 1.5 and 8.5 percentage points

1 The dataset covers countries of all levels of development, although (as usual) especially some highly underdeveloped countries had to be excluded due to missing data.

${ }^{2}$ We made use of the Im-Pesaran-Shin Test to ensure that the employed data is stationary. The test results are available from the authors on request.

3 Due to space restrictions we refrain from reporting the complete estimation results here; however, they are available from the authors on request. The explanatory power of the estimations as measured by adjusted R squared ranges in between 0,10 and 0,11 . 
(depending on the specification). Thus, we find strong supporting evidence for the hypothesis that droughts have significant long-lasting effects on economic growth.
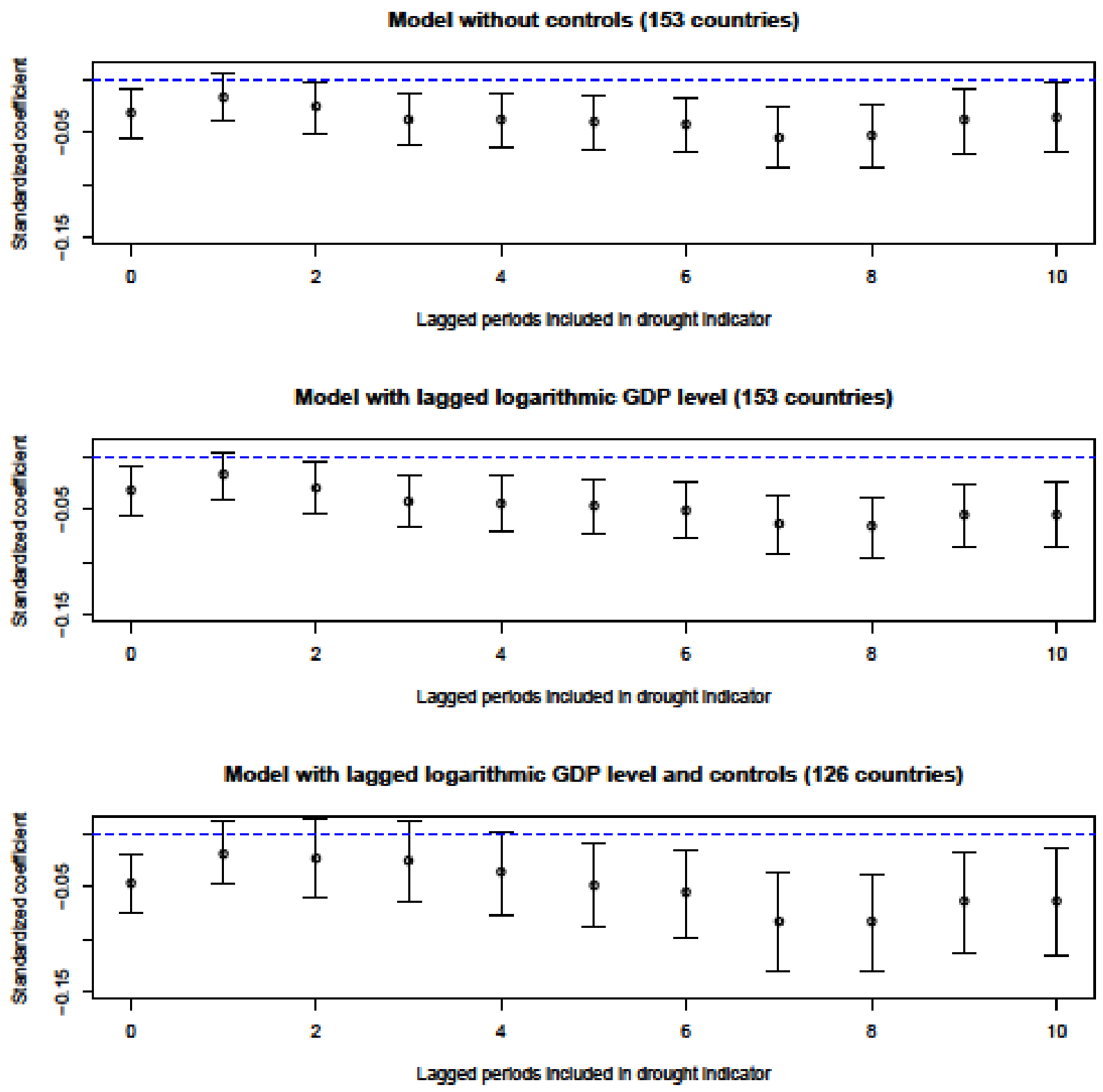

Figure 1: Estimation results for growth effects of droughts for alternative specifications (point estimator and 90\%-confidence intervals)

In order to test the stability of our results we repeat the estimation for two alternative specifications. In a first alternative specification, shown in the middle of Figure 1, we additionally control for the level of development of a country by adding the logarithmic one-period ahead 
GDP level to the estimation equation, as it is typically done in growth regressions. ${ }^{4}$ When doing so, the estimated coefficients of the drought indicator slightly increase in absolute value. At the same time the $p$-values of the estimated coefficients increase. The estimated coefficients of the drought indicator further increase when employing the full set of control variables typically used in growth regressions (net fertility, education, savings rate and government consumption share) ${ }^{5}$ as shown in the lower part of Figure 1. However, the $p$-values of the drought indicator decrease in this specification, likely due to the earlier described over-controlling problem. Nevertheless, the estimated coefficients of the drought indicator remain significant at least for specifications including at least the preceding 5 years.

While we cannot document all estimations underlying Figure 1 here in length, due to space restrictions, we show the estimation results for the indicator covering the 5 years preceding the drought in Table 2. Whenever the initial GDP level is added to the regression equation it turns out to be significant and negative, as most growth theories predict. In the specification with full set of controls the savings rate (investment share) and the net fertility rate turn out to be significant. While a higher savings rate increases per-capita growth the opposite holds true for net fertility. Again, both findings are in line with conventional theories of economic growth. The other employed control variables turn out to be insignificant.

Table 2: Selected estimation results for 5-year drought indicator

(1)

Drought indicator $\mathrm{i}, \mathrm{t}, \mathrm{5}$

Ln GDP i, t-1

(0.0158)

Investment share $\mathrm{i}, \mathrm{t}-1$

Government share $\mathrm{i}, \mathrm{t}-1$

Net fertility rate $\mathrm{i}, \mathrm{t}-1$

Avg. years of total schooling $i, t-1$
(2)

$-0.0483 * * *$

(0.0159) $-1.4473 * * *$

(0.2273)
(3)

$-0.0500 * *$

$(0.0245)$

$-1.4543^{* * *}$

(0.2692)

(0.0418)

0.0224

(0.0487)

$-0.1054 *$

(0.0597)

$-0.0883$

(0.1111)

\begin{tabular}{lccc} 
Observations & 5035 & 5035 & 4127 \\
Countries & 153 & 153 & 126 \\
Adjusted $\mathrm{R}^{2}$ & 0.1054 & 0.1358 & 0.1520 \\
\hline
\end{tabular}

\footnotetext{
${ }^{4}$ When including the logarithmic level of GDP as control the resulting model might suffer from the well-known Nickell Bias (Nickell 1981). However, as the average time dimension of our panel data is large (36 years) it seems to be appropriate to assume that the remaining bias is small enough to be neglected. The explanatory power of the estimations as measured by adjusted $R$ squared ranges in between 0,13 and 0,14.

${ }^{5}$ In all specifications significant control variables have the expected sign. The explanatory power of the estimations as measured by adjusted $R$ squared ranges in between 0,15 and 0,16.
} 
$* * *, * *, *$ denote significance at the $1 \%, 5 \%$ and $10 \%$ level, respectively. Spatially corrected HAC standard errors reported in parentheses. Country and time fixed effects are included but not reported.

\section{Does the Effect of Droughts Differ between Rich and Poor Countries?}

Earlier empirical findings (see e.g. Skidmore and Toya 2007 or Kahn 2004) have pointed into the direction that certain types of natural disasters might have different effects in rich and in comparatively poor countries, for example because comparatively rich countries can invest more resources into disaster prevention and mitigation measures. In order to study potential differences in drought-effects we subdivided our sample into two subsamples. The first subsample consists of 29 countries which are classified as high income countries by the World Bank. The remaining 122 countries form the second subsample. For both subsamples we repeat the two-way fixed effects estimation. 

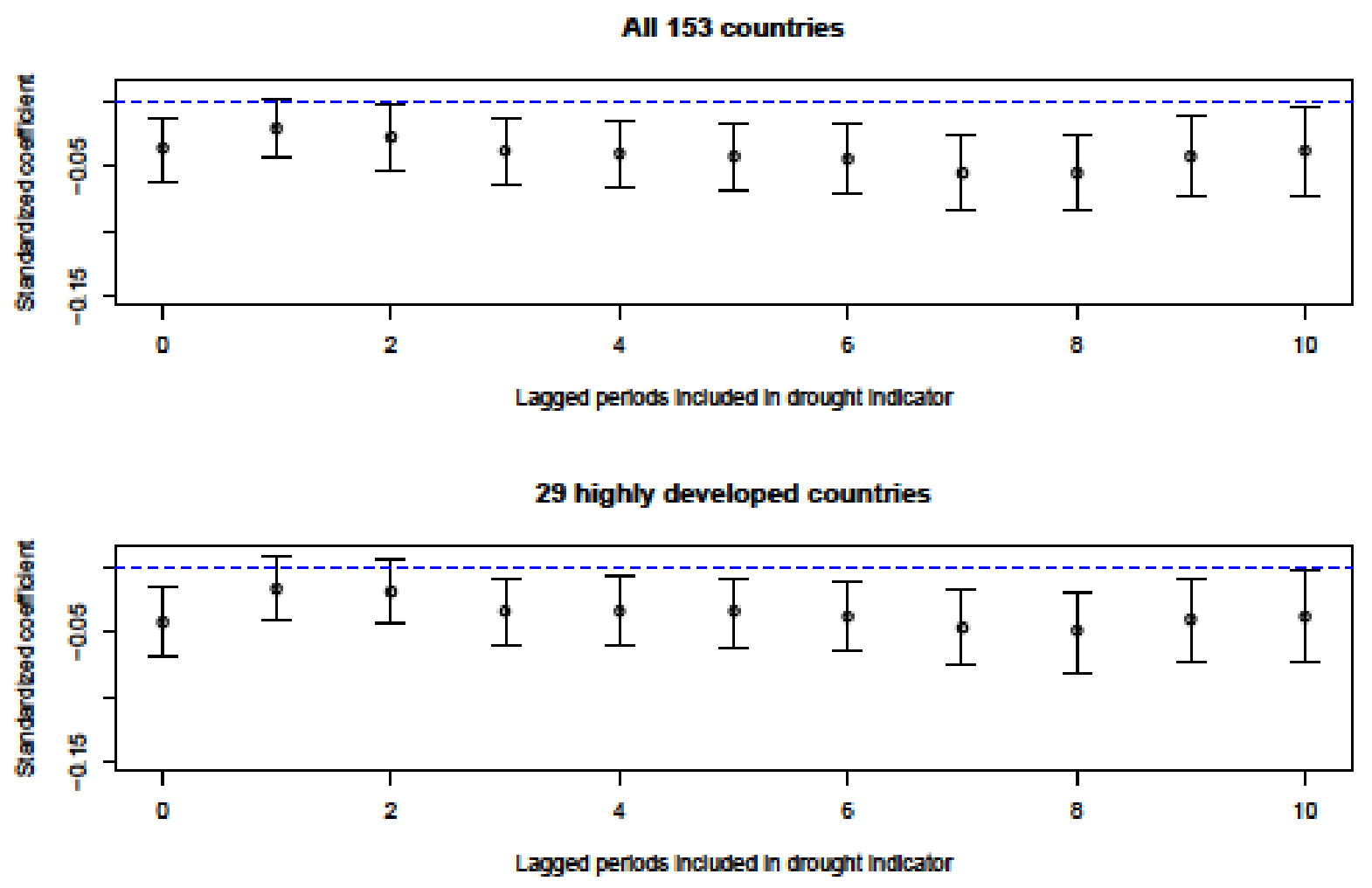

122 less developed countries

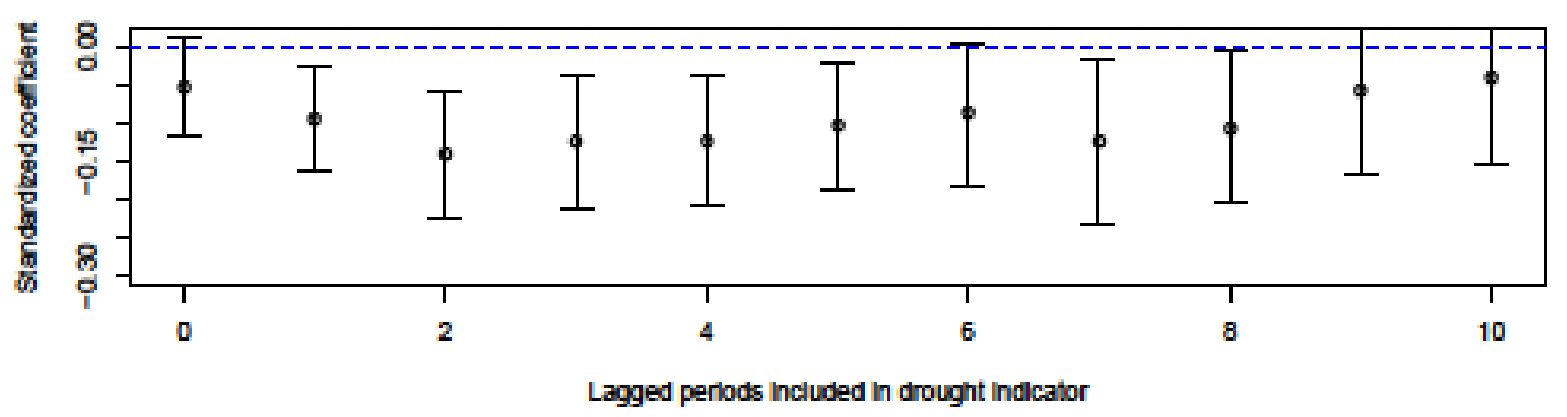

Figure 2: Estimation results for growth effects of droughts for country groups (point estimator and 90\%-confidence intervals)

The estimation results for the drought indicators are shown in Figure 2. The results indicate that in both highly developed and less developed countries droughts tend to affect economic growth negatively, although the time patterns differ to some extent. Moreover and in line with the earlier cited literature, we find the effects of droughts to be much larger in the sample of less developed countries. 


\section{Transmission Channels}

As our previous analysis has detected significantly negative long-run effects of droughts one might be interested in the question, through which channels droughts affect long-run economic growth. Because long-run growth effects themselves have only rarely been studied it does not come as a surprise that only scarce evidence is yet available on the issue of transmission channels of natural disasters in general and droughts in particular. The natural candidates for transmission channels can be identified on the basis of theories of economic growth. Although the factors determining long-run growth naturally differ to some extent in between competing theories, factors such as the savings rate, the rate of population growth and human capital play a decisive role in almost all modern growth theories. We therefore concentrate our analysis on these growth factors and study whether the savings rate, net fertility and education are affected by occurring droughts.

Saving is typically seen as a means of consumption smoothing. Naturally, the amount of saving will increase with a corresponding increase in life expectation. Whenever natural disasters pose a risk to life, this likely increases consumption and depresses saving. However, the theory of precautionary saving argues that saving does not only serve to spread income over the life cycle, but might also serve as insurance against uncertain events (Lusardi 1998). In this context, Roson et al. (2005) argue that individuals might react to natural disasters by increasing their savings. However, it is also possible that precautionary saving is reduced as a consequence of natural disasters. Often individuals who have suffered from catastrophic losses are supported or even compensated by state institutions, private donations, or international aid. All these forms of support decrease the incentives for accumulating one's own precautionary savings.

Natural disaster risk might also affect population growth. Especially in less developed countries children are a means of smoothing consumption over time (Guarcello, Mealli and Rosati 2010). Whenever households experience losses of income and/or wealth, the birth of additional children can, at least in the medium- and long-run, help the parents to enhance their financial situation, e.g. by generating supplemental income or taking over roles in family life which allows both parents to be part of the labor force. Whenever disaster risk poses not only a threat to income and wealth but also to life, parents might choose to increase their number of children as an insurance against child mortality (Schultz 1997).

Finally, human capital accumulation might be affected by natural disaster risk. On the one hand, natural disasters tend to reduce the expected return to physical capital, which should increase the incentive to invest in human capital (Skidmore and Toya, 2002). On the other hand, whenever disaster risk also increases mortality, the return of educational investments decreases and makes human capital accumulation less attractive (Checchi and Garcia-Penalosa 2004). Natural disasters might also have negative effects of human capital accumulation via decreasing educational attainment, e.g. in consequence of evacuations, increasing drop-out rates or school switching (Sacerdote 2012). 
Education channel (Model without controls)

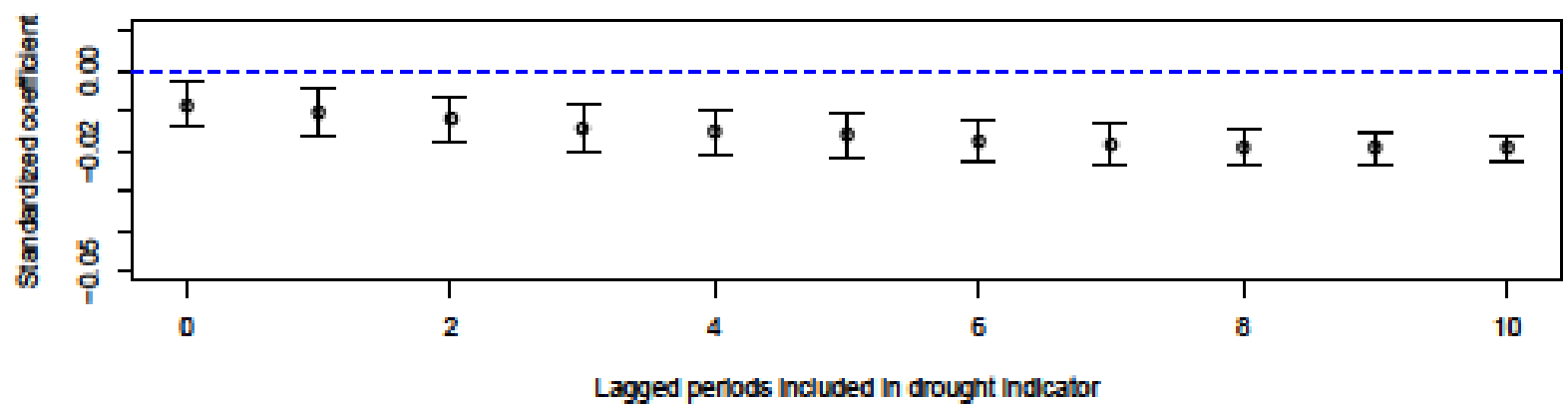

Saving channel (Model without controls)

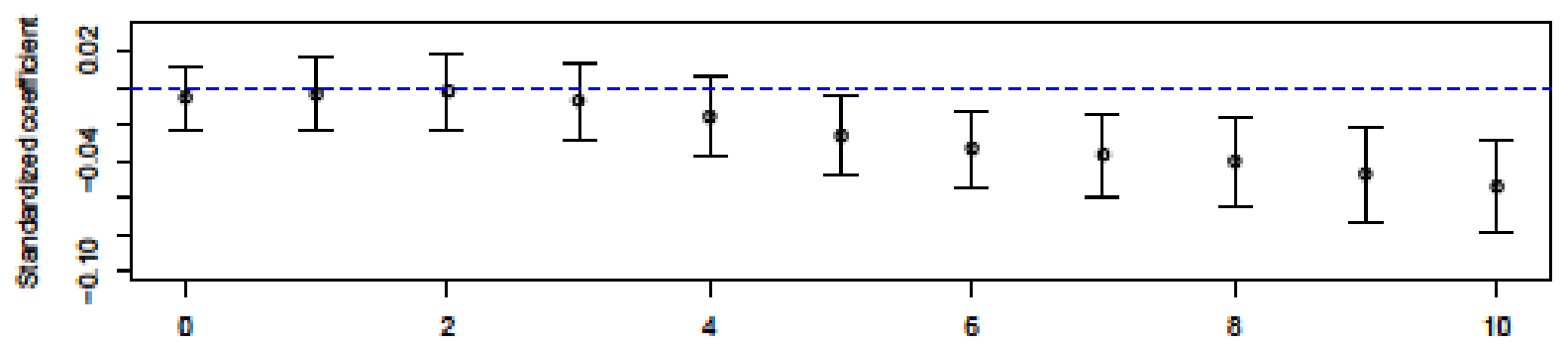

Lagged periods included in drought Indlcator

Fertility channel (Model without controls)

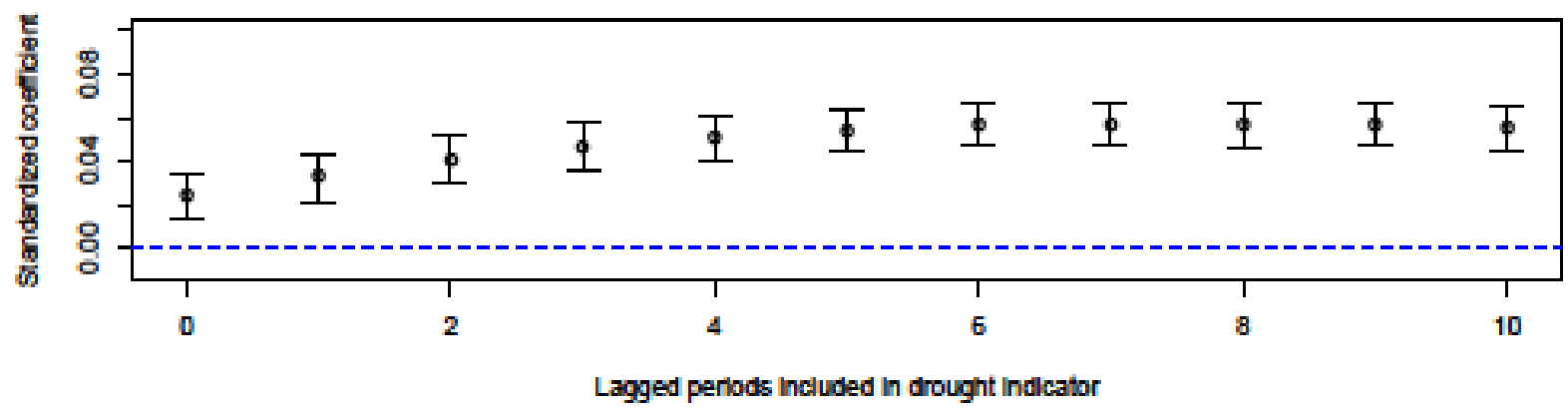

Figure 3: Estimation results for alternative transmission channels of droughts (point estimator and $90 \%$-confidence intervals)

In order to investigate the relevance of the discussed transmission channels empirically we apply the same estimation approach employed earlier to study the long-term growth effects of droughts, i.e. two-way fixed effects panel regressions with spatially corrected HAC standard 
errors. ${ }^{6}$ In order to avoid multicollinearity problems we again refrain from using additional control variables. ${ }^{7}$

In the upper part of figure 3 we show the effects of a one standard deviation increase in the drought indicator on the average years of total schooling. The estimated effect is negative and significant for all versions of the indicator. Thus, droughts tend to depress human capital formation. Our results coincide with the relatively small existing empirical literature which mostly finds negative effects of natural disasters on human capital accumulation. Alderman, Hoddinott and Kinsey (2006) study the effect of droughts on human capital formation in rural Zimbabwe and find a significantly negative effect on the number of completed school grades. Alston and Kent (2006) study the drought impact in secondary education access in Australia's rural and remote areas based on interviews and find evidence that droughts decrease human capital formation on the level of primary as well as on high schools. Cuaresma (2010), based on a sample of 80 countries over the period of 1980 to 2000, finds geologic disasters to depress secondary school enrollment while no such effect exists for climatic disasters. Kim (2010) studies the effect of two droughts in Cameroon and Burkina Faso based on a combination of survey and EMDAT data. While he finds a significantly negative effect of the 1990 drought on primary school completion in Cameroon, the effect for the 1988 drought in Burkina Faso turns out to be insignificant. ${ }^{8}$

In the middle part of figure 3 we show the effects of a one standard deviation increase in droughts on saving. The saving rate tends to react to droughts; all estimated coefficients turn out to be negative. However, the effect is significantly different from zero only when basing the drought indicator on at least the 5 preceding periods. Thus, droughts tend to depress saving at least in the medium term perspective. To the best of our knowledge the only related study by Skidmore and Toya (2002) found a negative but insignificant effect of climatic disasters on saving.

In the lower part of figure 3 we show the effects of a one standard deviation increase in the drought indicator on net fertility. The estimated coefficient is positive and significant for all variants of the indicator. Thus, droughts tend to increase net fertility, a result which is in line with the scarce empirical evidence on different types of natural disasters on fertility. In their empirical analysis of the December 2004 Indian Ocean Tsunami Nobles, Frankenberg and Thomas (2014) find a subsequent increase in fertility in the affected region. Finlay (2009) studies the fertility reaction after three huge earthquakes in India, Pakistan and Turkey and again reports long-lasting increases of fertility rates.

\footnotetext{
${ }^{6}$ Again we made use of the Im-Pesaran-Shin Test to check whether the employed data is stationary. The test results are available from the authors on request.

7 The results are similar when using the initial GDP level to control for countries' level of development. The results are available from the authors on request.

${ }^{8} \mathrm{Kim}$ (2010) also shows that wild fires in Mongolia reduced the probability to complete secondary school significantly.
} 


\section{Summary and Conclusions}

In this paper, we extend the existing literature on the long-term growth effects of natural disasters by studying the effects of droughts, based on a meteorological indicator constructed from rainfall data. We find systematically negative effects of droughts on the long-term growth performance of drought-affected countries which are of economically meaningful size and work through at least three different channels: lower education levels, lower saving rates and higher fertility.

The importance of this finding can be highlighted in the context of Integrated Policy Assessment Models (IAMs) which are the most widely used instrument of forecasting the economic consequences of climate change (see e.g. Metcalf and Stock 2015). As a prominent example, these models are used to estimate the necessary levels of carbon taxes to be able to reach pre-defined emission targets. IAMs combine information about human behavior and climate systems. An integral part of IAMs are damage functions. A major issue in modeling damage functions is whether climate (or climate-induced natural disasters) affects the level of output, as most IAMs assume, or impacts the growth path of output (Dell, Jones and Olken 2014). As the dynamic specification of the damage function has a huge impact on the forecast results and thus on the policy conclusion derived from IAMs a better empirical foundation of the damage function is highly important. Our results indicate that damage functions should assume climate to affect the path of output growth rather than only the level of output.

\section{References}

Alderman, H., Hoddinott, J., Kinsey, B., 2006. Long Term Consequences of Early Childhood Malnutrition, Oxford Economic Papers 58(3), 450-474.

Alston, M., Kent, J., 2006. The impact of drought on secondary education access in Australia's rural and remote areas. Centre for Rural Social Research (ILWS), Charles Sturt University, Wagga Wagga.

Barro, R., Lee, J.-W., 2013. A New Data Set of Educational Attainment in the World, 1950-2010. Journal of Development Economics 104, 184-198.

Cavallo, E., Noy, I., 2011. Natural Disasters and the Economy - A Survey. International Review of Environmental and Resource Economics 5, 63-102.

Checchi, D., Garcia-Penalosa, C., 2004. Risk and the Distribution of Human Capital. Economics Letters 82, 53-61.

Conley, T., 1999. GMM Estimation with Cross Sectional Dependence. Journal of Econometrics 92(1), 1-45.

Cuaresma, J.C., 2010. Natural Disasters and Human Capital Accumulation. World Bank Economic Review 24(2), 280-302.

Dell, M., Jones, B.F., Olken, B.A., 2014. What Do We Learn from the Weather? The New ClimateEconomy Literature. Journal of Economic Literature 52, 740-798.

Feenstra, R. C., Inklaar R., Timmer, M.P., 2015. The Next Generation of the Penn World Table. American Economic Review, forthcoming; available for download at www.ggdc.net/pwt. 
Felbermayr, G.J., Gröschl, J., 2014. Naturally Negative: The Growth Effects of Natural Disasters. Journal of Development Economics 111, 92-106.

Fetzer, T., 2014. Can Workfare Programs Moderate Violence? Evidence from India. STICERD Working Paper, http://www.trfetzer.com/job-market-paper/.

Finlay, J. E., 2009. Fertility Response to Natural Disasters. The Case of Three High Mortality Earthquakes. World Bank Policy Research Working Paper No. 4883, World Bank, Washington D.C.

Guarcello, L., Mealli, F., Rosati, F., 2010. Household vulnerability and child labor: the effect of shocks, credit rationing, and insurance. Journal of Population Economics 23(1), 169-198.

Hsiang, S.M., 2010. Temperatures and cyclones strongly associated with economic production in the Caribbean and Central America. PNAS 107 (35), 15367-15372.

Hsiang, S.M., Jina, A.S., 2014. The Causal Effects of Environmental Catastrophe on Economic Growth: Evidence from 6,700 tropical cyclones. NBER Working Paper No. 20352.

Jaramillo, C.R.H. 2009. Do Natural Disasters Have Long-Term Effects on Growth? Universidad de los Andes, mimeo.

Kahn, M. E., 2004. The death toll from natural disasters: The role of income, geography, and institutions. Review of Economics and Statistics 87(2), 271-284.

Kim, N., 2010. Impact of Extreme Climate Events on Educational Attainment: Evidence from Cross Section Data and Welfare Projection. In: Risk, Shock, and Human Development: On the Brink, Fuentes-Nieva, R., Seck, P.A. (eds.), Palgrave Macmillan, London.

Lusardi, A., 1998. On the Importance of the Precautionary Saving Motive. American Economic Review, Papers and Proceedings 88, 449-453.

Newey, W.K. and West, K.D., 1997. A Simple, Positive Semi-Definite, Heteroskedasticity and Autocorrelation Consistent Covariance Matrix. Econometrica 72(1), 703-708.

Nobles, J., Frankenberg, E., Thomas, D., 2014. The Effects of Mortality on Fertility: Population Dynamics after a Natural Disaster, NBER Working Paper No. 20448, Cambridge/Mass.

Noy, I., Nualsri, A., 2007. What do exogenous shocks tell us about growth theories? Working Papers, Santa Cruz Center for International Economics 07-16.

McKee, T.B., Doesken, N.J., Kleist, J., 1993. The relationship of drought frequency and duration to time scale. Proceedings of the Eighth Conference on Applied Climatology, Anaheim, American Meteorological Society, Boston, 179-184.

Metcalf, G., Stock, J., 2015. The Role of Integrated Assessment Models in Climate Policy: A User's Guide and Assessment. Discussion Paper 2015-68. Cambridge, Mass.: Harvard Project on Climate Agreements.

Nickell, S., 1981. Biases in dynamic models with fixed effects. Econometrica 49, 1417-1426.

Raddatz, C., 2009. The wrath of God: macroeconomic costs of natural disasters. World Bank Policy Research Working Paper No. 5039.

Roson, R., Calzadilla, A., Pauli, F., 2005. Climate Change and Extreme Events: an Assessment of Economic Implications. Computing in Economics and Finance 49, Society for Computational Economics.

Sacerdote, B., 2012. When the Saints Come Marching in: Effects of Hurricane Katrina and Rita on Student Evacuees. American Economic Journal: Applied Economics 4(1), 109-135.

Schultz, T.P., 1997. Demand for Children in Low Income Countries. In: Rosenzweig, M.R., Stark, O. (Eds.), Handbook of Population and Family Economics, North-Holland, Amsterdam, 349430. 
Skidmore, M., Toya, H., 2002. Do natural disasters promote long-run growth? Economic Inquiry 40, 664-687.

Skidmore, M., Toya, H., 2007. Economic development and the impacts of natural disasters. Economic Letters 94, 20-25.

Strobl, E., 2012. The economic growth impact of natural disasters in developing countries: Evidence from hurricane strikes in the Central American and Caribbean regions. Journal of Development Economics 97, 130-141.

Thomas, V., 2014. Confronting Climate-Related Disasters in Asia and the Pacific. Review of Economics 65, 193-207.

World Meteorological Organization, 2012. Standardized Precipitation Index. User Guide. WMO Geneva. 